\title{
Composite Films of Arabinoxylan and Fibrous Sepiolite: Morphological, Mechanical,
} and Barrier Properties

Sárossy, Zsuzsa ; Blomfeldt, J.O.; Hedenqvist, Mikael S. ; Bender Koch, Christian ; Sinha Ray, Suprakas ; Plackett, David

\section{Published in:}

A C S Applied Materials and Interfaces

Link to article, DOI:

10.1021/am3002956

Publication date:

2012

Document Version

Publisher's PDF, also known as Version of record

Link back to DTU Orbit

Citation (APA):

Sárossy, Z., Blomfeldt, J. O., Hedenqvist, M. S., Bender Koch, C., Sinha Ray, S., \& Plackett, D. (2012).

Composite Films of Arabinoxylan and Fibrous Sepiolite: Morphological, Mechanical, and Barrier Properties. A C S Applied Materials and Interfaces, 4, 3378-3386. https://doi.org/10.1021/am3002956

\section{General rights}

Copyright and moral rights for the publications made accessible in the public portal are retained by the authors and/or other copyright owners and it is a condition of accessing publications that users recognise and abide by the legal requirements associated with these rights.

- Users may download and print one copy of any publication from the public portal for the purpose of private study or research.

- You may not further distribute the material or use it for any profit-making activity or commercial gain

- You may freely distribute the URL identifying the publication in the public portal 


\title{
Composite Films of Arabinoxylan and Fibrous Sepiolite: Morphological, Mechanical, and Barrier Properties
}

\author{
Zsuzsa Sárossy, ${ }^{\dagger}$ Thomas O. J. Blomfeldt, ${ }^{\ddagger}$ Mikael S. Hedenqvist, ${ }^{\ddagger}$ Christian Bender Koch, ${ }^{\S}$ \\ Suprakas Sinha Ray, ${ }^{\perp}$ and David Plackett* ${ }^{* \dagger}$ \\ ${ }^{\dagger}$ Department of Chemical and Biochemical Engineering, Technical University of Denmark, DK-2800 Kgs. Lyngby, Denmark \\ ${ }^{\ddagger}$ Department of Fibre and Polymer Technology, KTH Royal Institute of Technology, SE-100 44 Stockholm, Sweden \\ ${ }^{\S}$ Department of Chemistry, University of Copenhagen, Thorvaldsensvej 40, DK-1871 Frederiksberg C, Denmark \\ ${ }^{\perp}$ DST/CSIR Nanotechnology Innovation Centre, National Centre for Nano-Structured Materials, Council for Scientific and \\ Industrial Research, P.O. Box 395, Pretoria 0001, Republic of South Africa
}

ABSTRACT: Hemicelluloses represent a largely unutilized resource for future bioderived films in packaging and other applications. However, improvement of film properties is needed in order to transfer this potential into reality. In this context, sepiolite, a fibrous clay, was investigated as an additive to enhance the properties of rye flour arabinoxylan. Composite films cast from arabinoxylan solutions and sepiolite suspensions in water were transparent or semitransparent at additive loadings in the 2.5-10 wt \% range. Scanning electron

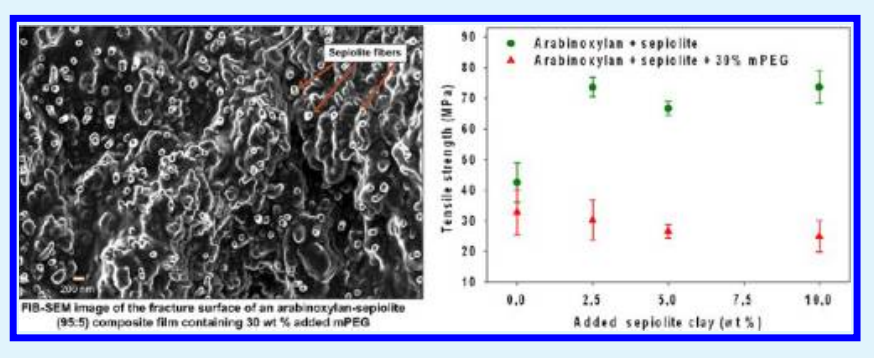
microscopy showed that the sepiolite was well dispersed in the arabinoxylan films and sepiolite fiber aggregation was not found. FT-IR spectroscopy provided some evidence for hydrogen bonding between sepiolite and arabinoxylan. Consistent with these findings, mechanical testing showed increases in film stiffness and strength with sepiolite addition and the effect of poly(ethylene glycol) methyl ether ( $\mathrm{mPEG)}$ ) plasticizer addition. Incorporation of sepiolite did not significantly influence the thermal degradation or the gas barrier properties of arabinoxylan films, which is likely a consequence of sepiolite fiber morphology. In summary, sepiolite was shown to have potential as an additive to obtain stronger hemicellulose films although other approaches, possibly in combination with the use of sepiolite, would be needed if enhanced film barrier properties are required for specific applications.

KEYWORDS: arabinoxylan, sepiolite, composite film, mPEG, tensile properties, barrier properties

\section{INTRODUCTION}

Plant polysaccharides derived as byproducts from agricultural processes have lately received much attention as substrates for potential future packaging materials. ${ }^{1-4}$ Xylan-type hemicelluloses are the most abundant heteropolysaccharides in agricultural residues and there has been increasing interest in their use in food packaging and other applications. ${ }^{5}$ Indeed, over the past few years, there have been a number of reports discussing films prepared from xylans extracted from aspen or beech, barley husks, oat spelts, wheat bran, rye grains, or corn hulls and bran. ${ }^{1-3,6,7}$ Agricultural byproducts such as oat spelt or barley husk arabinoxylans have been shown to provide good oxygen and/or grease barrier films in applications where moderately high water vapor permeability is required. ${ }^{1,2}$ Hemicelluloses are hydrophilic polysaccharides and films tend to show poor properties in highly humid environments,and, on the application, mechanical properties may also need improvement. For these reasons, research on new and improved hemicellulose films continues to be reported. ${ }^{3,8-10}$

A potential route to improving mechanical and barrier properties is the addition of nanofillers to form hemicellulosebased nanocomposites. In comparison to unmodified polymers, the characteristic features of nanocomposites generally include higher modulus, increased strength, decreased gas permeability and increased thermal stability. These effects are in large part due to the high surface area of the well-distributed nanoparticles and the resulting increased interfacial area. ${ }^{11-13}$ Claybiopolymer nanocomposites are of particular interest because of the significant potential to improve material properties; however, in the case of hemicelluloses, the number of publications discussing the effects of clay nanofiller addition remains quite limited. ${ }^{13,14}$ Xylan-clay films have been made focusing on the use of layered silicate clays such as montmorillonite (MMT). For example, Ünlü et al. ${ }^{14}$ prepared films using corn cob xylan and MMT. Their research using electrokinetic, rheological and crystallinity measurements suggested that interactions took place on the MMT surface and that the xylans were not oriented into the MMT interlayer spaces.

Received: February 20, 2012

Accepted: June 3, 2012

Published: June 3, 2012 


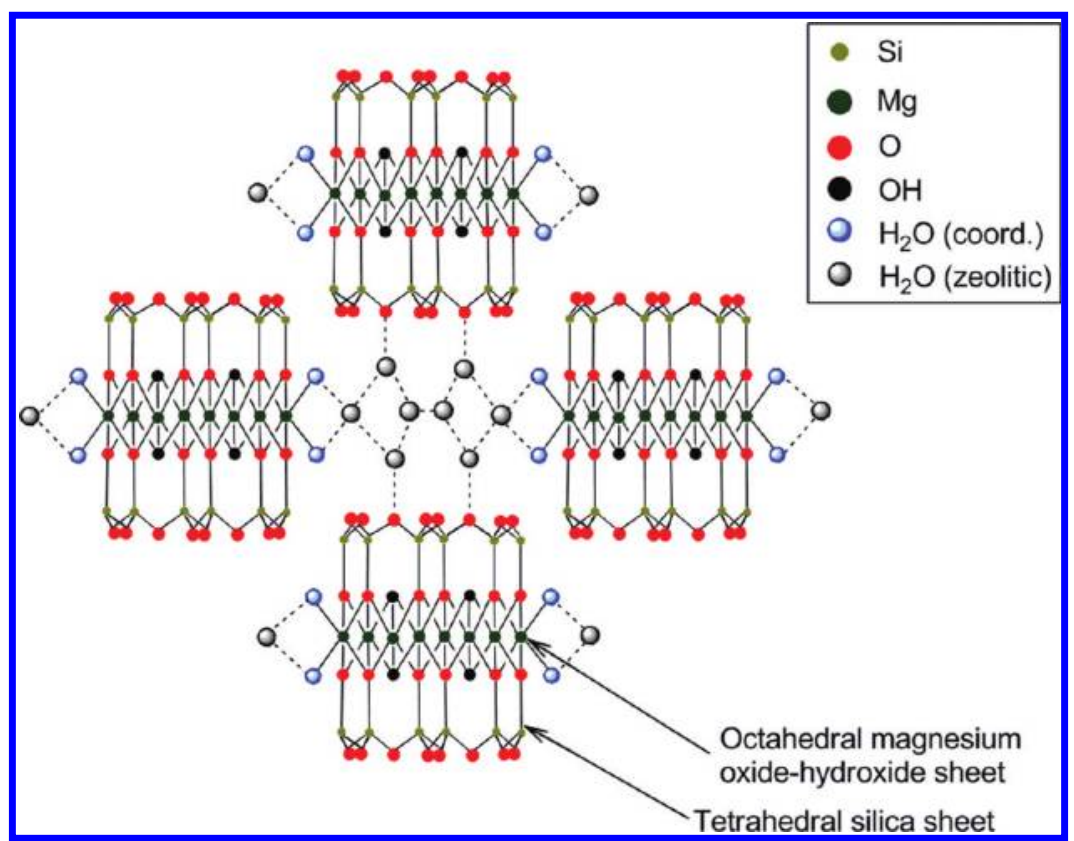

Figure 1. Transection of the sepiolite structure. Adapted from ref 24 .

In addition to the use of MMT, the interesting potential of other clays having tubular or fibrous morphologies has been recognized. In the case of sepiolite, a fibrous clay, researchers have investigated its use as a filler in natural rubber and plastics such as poly(vinyl chloride). ${ }^{15}$ Combinations of sepiolite with biopolymers such as starch, chitosan, gelatin, and polylactide have also been investigated. ${ }^{12,16-18}$ As one example, biocompatible biomaterials were prepared with collagen and sepiolite and used as gel-like complexes. ${ }^{19}$ Improved mechanical properties were found in these sepiolite/biopolymer nanocomposites, which is in general comparable with the improvements obtained with other fiber-like nanofillers (e.g., cellulose whiskers). Chivrac et al. ${ }^{12}$ studied the effects of sepiolite addition on the mechanical properties of starch nanocomposites. In their study a comparison was made between sepiolite and other fibrous fillers, such as cellulose whiskers or cellulose nanofibers, as well as hectorite, a layered nanoclay. Evidence for strong hydrogen bonding was noted at cellulose whisker loadings above the percolation threshold. Reinforcing effects were observed when either cellulose whiskers or cellulose nanofibers were used and in both cases mechanical property improvements were similar to those achieved when using a layered or fibrous clay additive. In these composites, the Young's modulus increased and there was no effect on the strain at break. When fibrous sepiolite and MMT were compared, it was found that sepiolite increased the Young's modulus and tensile strength to a greater extent than MMT, presumably due to the morphology of the clay, the increased crystallinity of the nanocomposites and interaction between the starch matrix and sepiolite.

Sepiolite has a hydrated magnesium silicate composition with a theoretical unit-cell formula equivalent to $\mathrm{Si}_{12} \mathrm{O}_{30} \mathrm{Mg}_{8}(\mathrm{OH})_{4} \cdot\left(\mathrm{H}_{2} \mathrm{O}\right)_{4} \cdot 8 \mathrm{H}_{2} \mathrm{O}$. Alternating longitudinal blocks and channels (tunnels) are found in the sepiolite structure, producing long needles with a high surface area (approximately $374 \mathrm{~m}^{2} / \mathrm{g}$ ). ${ }^{11}$ The blocks are built up of two layers of tetrahedral silica, sandwiching an octahedral magnesium oxide-hydroxide layer in the center (Figure 1). The composite layers are off-set, hence allowing the formation of tunnel-like micropores (channels), running parallel to the fiber axis. The channels in the sepiolite structure are occupied by water coordinated to the magnesium ions at the edges of the octahedral layers and zeolitic water associated with the clay structure by hydrogen bonding inside the tunnels. Silanol (Si$\mathrm{OH}$ ) groups appear at the external surface edges of the sepiolite structure. $^{12,20-22}$ The numerous silanol groups provide sites for hydrogen bonding and Van der Waals interactions in composites, contributing to the reinforcing effect of sepiolite. From this perspective, the availability of silanol groups for hydrogen bonding with other moieties mostly occurs at the edges. Sepiolite has a microfibrous morphology with fiber lengths of $2-10 \mu \mathrm{m}$ and diameters in the range of $2-100$ $\mathrm{nm},{ }^{17,23}$ pointing to aspect ratios of $20-200$.

We focused our work on composite films using arabinoxylan from rye grains and sepiolite at loadings between 2.5 and $10 \mathrm{wt}$ $\%$. The objective was to observe potential improvements in the mechanical and barrier properties of arabinoxylan films. Morphology, crystallinity and structural changes in the composite films were studied as well as tensile and barrier properties and these characteristics were compared with those of unreinforced arabinoxylan films. To the best of our knowledge, this is the first report on the production and mechanical/barrier properties of sepiolite-hemicellulose composite films.

\section{MATERIALS AND METHODS}

Materials. Arabinoxylan (Lot 20601) from rye flour (RAX) was purchased from Megazyme International Ireland Ltd. (Bray, Ireland). The arabinoxylan was a high-viscosity sample with reported Ara/Xyl ratio of 0.64 , purity $~ 90 \%$ and ash content of 4.5 wt \%. Poly(ethylene glycol) methyl ether (mPEG) and sepiolite were purchased from Sigma-Aldrich (Steinheim, Germany). The sepiolite powder from Aldrich has a unit cell formula of $\mathrm{Mg}_{2} \mathrm{H}_{2} \mathrm{Si}_{3} \mathrm{O}_{9} \cdot x \mathrm{H}_{2} \mathrm{O}$ and a reported $\mathrm{Mg}$ content of approximately $13 \%$.

Film Casting. Neat RAX and RAX-sepiolite composite films containing the two components in ratios 97.5:2.5, 95:5, 90:10, and 80:20 were prepared, although the last of these, containing $20 \mathrm{wt} \%$ sepiolite, was prepared only for tests on light transmission. RAX was mixed into MilliQ water for $4 \mathrm{~h}$ at $70{ }^{\circ} \mathrm{C}$ under magnetic stirring at a 


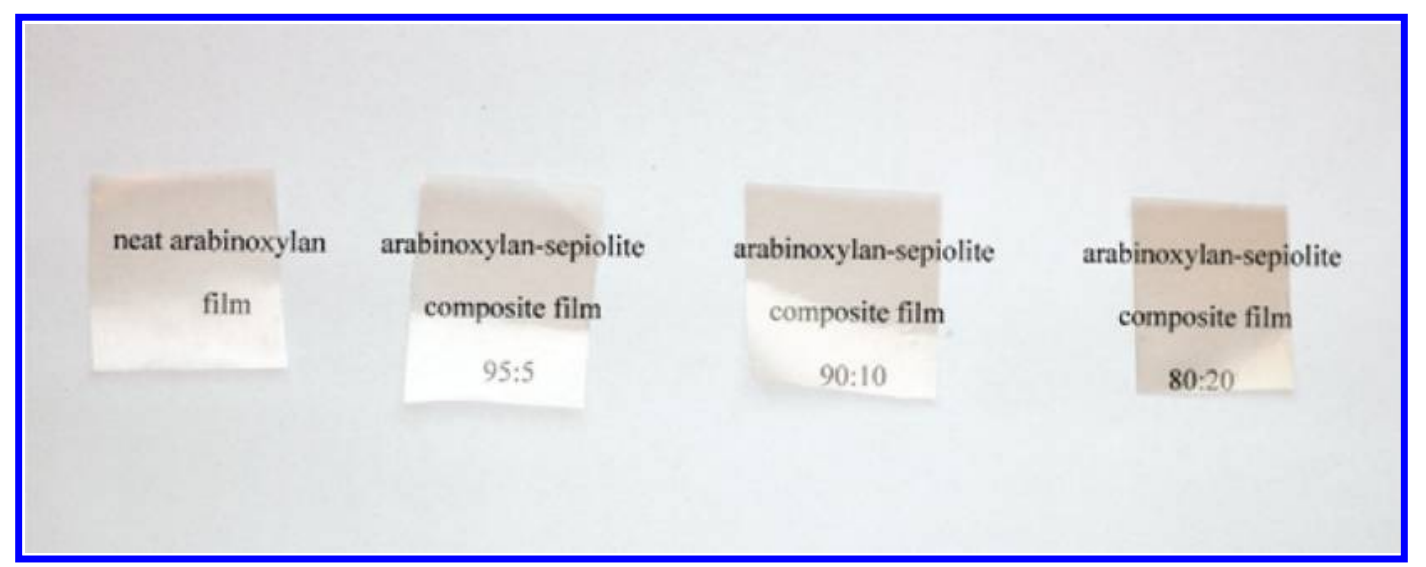

Figure 2. Images of neat rye arabinoxylan (RAX) and rye arabinoxylan (RAX)-sepiolite composite films, from left to right, RAX, RAX-sepiolite 95:5, 90:10, and 80:20. Films were placed on a white paper sheet with printed text.

concentration of $10 \mathrm{~g} / \mathrm{L}$. Sepiolite suspensions were prepared at a concentration of $2.5 \mathrm{~g} / \mathrm{L}$ in MilliQ water and were sonicated for one hour under magnetic stirring using a UP $400 \mathrm{~S}$ ultrasonic processor with a $22 \mathrm{~mm}$ diameter tip and a maximum amplitude of $100 \mu \mathrm{m}$ at $25 \%$ output (Hielscher Ultrasonics GmbH, Teltow, Germany). The sepiolite suspension and RAX solution were then mixed in appropriate ratios using magnetic stirring. The mixtures were degassed by ultrasonication for $15 \mathrm{~min}$ and suitable volumes poured into Tefloncoated Petri dishes for the purpose of film casting. In selected cases, mPEG plasticizer was added to the mixed RAX-sepiolite formulations prior to ultrasonication at $30 \mathrm{wt} \%$ loading on the basis of total RAXsepiolite weight. mPEG was chosen as the plasticizer as it is nontoxic and may be applied in foods, cosmetics or pharmaceuticals. ${ }^{25} \mathrm{mPEG}$ has not to our knowledge been used as a plasticizer in previous studies on hemicellulose films. Films were prepared by drying the contents of the Petri dishes at $23{ }^{\circ} \mathrm{C}$ and $50 \%$ relative humidity (RH) and held under these conditions for at least four days before analysis. The thickness of the films was measured at 10 points using a Mega-Check Pocket Coating Thickness Meter with micrometer precision (ListMagnetik, Leinfelden-Echterdingen, Germany) and average film thicknesses were calculated.

Light Transmittance. The light transmittance of the films was measured for two replicates of each film type over the $190-890 \mathrm{~nm}$ wavelength range with an Ultrospec 2100 pro UV-visible spectrophotometer (Biochrom Ltd., Cambridge, UK). The light transmittance was normalized to a thickness of $30 \mu \mathrm{m}$ for all tested films. Film opacity, normalized to a film thickness of $30 \mu \mathrm{m}$ and expressed as absorbance $\times$ nanometers, was calculated with an integration procedure as similarly reported by Siró et al. ${ }^{26}$

Fourier Transform Infrared (FT-IR) Spectroscopy. FT-IR spectra were collected using a Perkin-Elmer Spectrum One spectrometer (PerkinElmer Life and Analytical Sciences, Shelton, WA, USA). For this purpose, the film samples were tested using an STI Thunderdome attenuated total reflectance (ATR) attachment. Sepiolite powder samples were pressed into $\mathrm{KBr}$ pellets $(2 \mathrm{mg}$ sample/ $200 \mathrm{mg} \mathrm{KBr}$ ). Spectra were obtained based on 16 scans collected in the range $400-4000 \mathrm{~cm}^{-1}$ at a resolution of $2 \mathrm{~cm}^{-1}$.

X-ray Diffraction. X-ray diffraction was used to study structural changes in RAX-sepiolite composite films in comparison to neat RAX film and sepiolite powder. A Siemens D5000 X-ray diffractometer (Siemens Analytical and X-Ray Instruments Inc., Madison, WI, USA) equipped with a Co $(\lambda=0.179 \mathrm{~nm})$ tube and a diffracted beam monochromator was used. Diffractograms were collected in the $2 \Theta$ range of $3-30^{\circ}$ using a step size of $0.05^{\circ}$ and a counting time of $20 \mathrm{~s}$. One film sample was tested from each cast film type.

Microscopy. The fracture surface morphology of the composites after tensile testing was studied using focused ion beam scanning electron microscopy (FIB-SEM) on an AURIGA CrossBeamWorkstation (Carl Zeiss, Oberkochen, Germany). The samples were sputter-coated with carbon in a vacuum chamber before examination.
The chemical composition of the composites was analyzed with energy-dispersive X-ray spectroscopy (EDX, NORAN System Six, Thermo Scientific, Waltham, MA) in a JEOL 7500F SEM (JEOL Ltd., Tokyo, Japan).

Thermogravimetric Analysis (TGA). The thermal degradation of films and sepiolite powder was studied under $\mathrm{N}_{2}$ atmosphere at a flow rate of $30 \mathrm{~mL} / \mathrm{min}$ using a Netzsch TG 209 F3 Tarsus thermogravimetric analyzer (NETZSCH-Gerätebau GmbH, Selb, Germany). The weight of the analyzed film pieces varied between 1 and $2 \mathrm{mg}$ and alumina pans were used for the measurements. The samples were heated from 36 to $900{ }^{\circ} \mathrm{C}$ at a rate of $20{ }^{\circ} \mathrm{C} / \mathrm{min}$, including an isothermal ramp at $120^{\circ} \mathrm{C}$ for three minutes.

Tensile Testing. Tensile testing was performed on rectangular film samples $(10 \mathrm{~mm} \times 80 \mathrm{~mm})$ using an Instron 5944 universal testing machine (Instron Corp., High Wycombe, England) with Instron grips series nr. 2712-019, according to the ASTM standard test method D882-09. ${ }^{27}$ Film test samples were cut using a Synrad 48-5 laser cutter (Synrad, Mukilteo, WA, USA). Sample testing was performed in a conditioned room at $23 \pm 1{ }^{\circ} \mathrm{C}$ and $50 \pm 2 \% \mathrm{RH}$. A load cell of $50 \mathrm{~N}$ was used with an extension rate of $5 \mathrm{~mm} / \mathrm{min}$ and an initial grip distance of $50 \mathrm{~mm}$. A preload of $0.1 \mathrm{~N}$ (extension rate $=5 \mathrm{~mm} / \mathrm{min}$ ) was applied to ensure measurement of straight samples. Ten specimens were tested from each sample, which were conditioned at $23{ }^{\circ} \mathrm{C}$ and $50 \% \mathrm{RH}$ for $120 \mathrm{~h}$ before testing.

Statistical analyses were performed on the tensile test results using Tukey-Kramer HSD (Honestly Significant Difference) tests on data from ten specimens and the statistical software JMP version 5.0.1 (SAS Institute Inc., Cary, NC, USA) at a significance level of 0.05 .

Water Vapor Permeability. The water vapor permeability was measured for three films per sample type according to the ASTM 96/E $96 \mathrm{M}-05$ standard. $^{28}$ Films were sealed to aluminum cups, containing $21 \mathrm{~g}$ dry $\mathrm{CaCl}_{2}$ as a desiccant. This setup included an air gap of $6 \mathrm{~mm}$ between the desiccant and the underside of the film. The aluminum cups were placed into a climate chamber with controlled relative humidity and temperature $\left(50 \% \mathrm{RH}\right.$ and $\left.23{ }^{\circ} \mathrm{C}\right)$. The cups were weighed 8-10 times over the period of three days. Calculations were performed according to the method of Mikkonen et al. ${ }^{29}$ The water vapor transmission rate (WVTR) was calculated from the linear regression of the slope of weight gain vs time by dividing the slope by the test cell mouth area. The water vapor permeability (WVP) was obtained by multiplying the WVTR by the thickness of the film and dividing it by the water vapor partial pressure difference between the two sides of the film. The correction method of Gennadios et al., ${ }^{30}$ in which the air gap is taken into account, was used as a means of calculating the water vapor partial pressure at the underside of the film. However, data calculated using this correction method gave WVP values which were not significantly different from those calculated without correction.

Oxygen Permeability. The oxygen transmission rate (OTR) of films was measured with an OPT-5000 Oxygen Permeability Tester 
(PBI-Dansensor A/S, Ringsted, Denmark) containing a ceramic solidstate oxygen sensor. Measurements were performed at $23 \pm 0.03{ }^{\circ} \mathrm{C}$ and $50 \pm 2 \% \mathrm{RH}$. The test samples were placed in a permeability chamber which consisted of an upper (feeding) and a bottom (receiving) chamber. Dry nitrogen containing less than $0.1 \mathrm{ppm}$ oxygen (Alphagaz 2, Air-Liquide Danmark) was used as carrier gas and pure oxygen (N45, Air-Liquide Danmark) served as the test gas. Inlet pressure was set to four bars at the regulator. The oxygen permeability was calculated by multiplying the OTR with the thickness of the films and dividing with the pressure value of the measuring chamber. The oxygen permeability was determined for two replicates of each film type.

\section{RESULTS AND DISCUSSION}

Visual Properties and Light Transmittance. All cast films were cohesive and the thickness of the films varied between 25 and $45 \mu \mathrm{m}$. Light transmittance showed a general decrease with increasing clay content. All cast films were at least semitransparent; however, minor color changes were visible as the clay loading was increased to 10 and $20 \mathrm{wt} \%$, as can be seen in Figure 2. The neat RAX films showed some slightly opaque spots, which may have been due to minor quantities of proteins precipitated during sample dissolution or lignin contamination. Significant contamination by lignin was not expected in the RAX since the material was alkali-extracted from rye grains and only minor amounts of aromatic components, such as ferulic acids, which would be characteristic of lignin, were found. Robertson et al. ${ }^{31}$ measured the ferulic acid content of the RAX material used in this study at a level of $1.55 \mathrm{mg} / \mathrm{g}$. The light transmittance of the films as a function of wavelength is shown in Figure 3. The neat RAX film and films

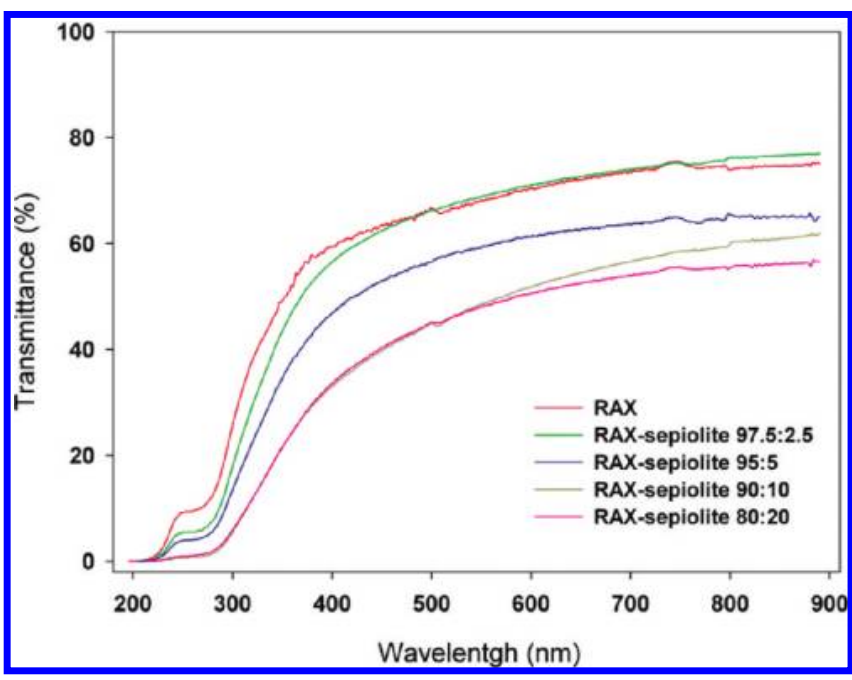

Figure 3. UV-vis transmittance of rye arabinoxylan (RAX) and RAXsepiolite composite films.

containing lower amounts of sepiolite (2.5 and 5 wt \%) showed a minor inflection in light transmission at $260 \mathrm{~nm}$. This finding could be attributable to some aromatic compounds such as lignin or proteins absorbing in the ultraviolet region, because the typical absorption of aromatic compounds such as ferulic acid or aromatic amino acids occurs in the range 200-300 $\mathrm{nm} .{ }^{32}$ The film opacities were calculated and a good correlation was found with the visual appearance. The calculated values were 276.2, 217.3, 328.0, 349.2, $398.5(\mathrm{AU} \times \mathrm{nm})$ for the RAX, RAX-sepiolite 97.5:2.5, 95:5, 90:10, and 80:20 films, respectively. These differences suggest that 5 wt $\%$ or higher amounts of added clay were not well dispersed and therefore introduced some opacity. ${ }^{33}$ This effect was particularly noticeable at 10 and $20 \mathrm{wt} \%$ sepiolite loadings.

Microscopy. The sepiolite distribution and the presence of clay aggregates was studied with FIB-SEM. Figure 4a shows the

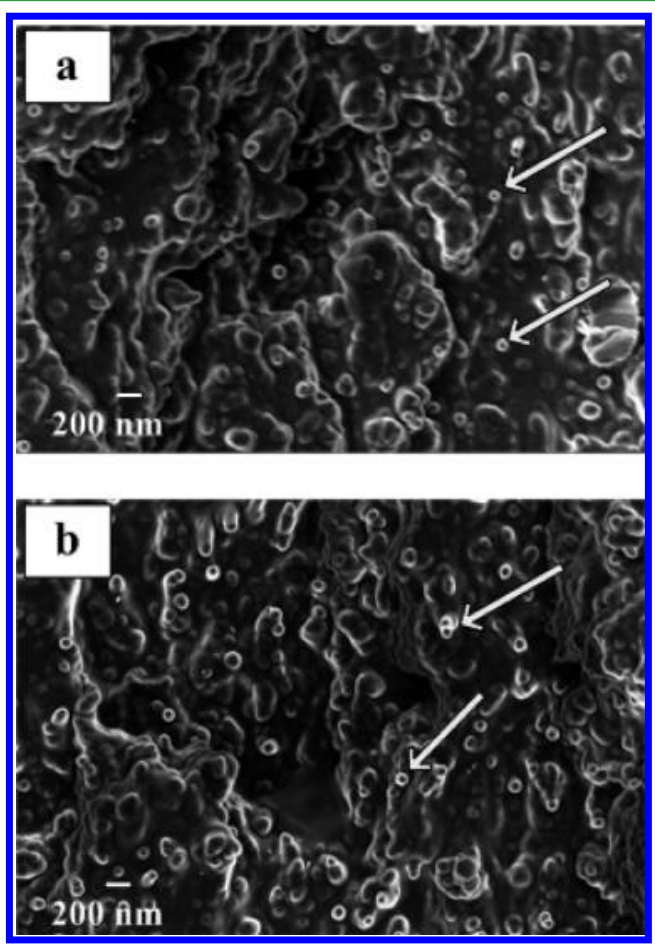

Figure 4. FIB-SEM images of rye arabinoxylan (RAX)-sepiolite composites, (a) RAX-sepiolite 97.5:2.5 and (b) RAX-sepiolite 95:5. Scale bar $=200 \mathrm{~nm}$. The arrows point to sepiolite fibers (fiber diameter: $100-200 \mathrm{~nm}$ ).

distribution of 2.5 wt \% sepiolite in the RAX matrix in the cross-section of tensile-tested films and Figure $4 \mathrm{~b}$ illustrates the composite film cross-section containing 5 wt \% sepiolite after tensile testing. The images show well-dispersed sepiolite fibers with minimal pull-outs, indicating strong binding between the sepiolite and the RAX matrix. The lower level of clay addition is apparent from the fewer fibers visible in the image of the RAXsepiolite 97.5:2.5 film (Figure 4a) which contains half the amount of sepiolite as the film RAX-sepiolite 95:5. The RAX matrix shows a nodular appearance and a similar morphology to that reported by Stevanic et al. ${ }^{34}$ in a study on arabinoxylanbacterial cellulose composite films based on the same RAX. From the FIB-SEM images, the diameter of the sepiolite fibers is estimated to be $\sim 100 \mathrm{~nm}$, which is comparable with values reported in an earlier study. ${ }^{17}$

The composition of the composite films was studied by energy-dispersive X-ray spectroscopy (EDX) (Figure 5). As expected, EDX analysis revealed the occurrence of silicon and magnesium in an approximate ratio of 1.5 to 1 (atomic ratio) due to the presence of sepiolite. Phosphorus and calcium, present in the pure RAX and dominating in the ash, were also detected in the films.

FT-IR Spectroscopy. FT-IR spectra of sepiolite powder, RAX, and RAX-sepiolite films were collected in order to examine the presence of clay in the RAX matrix as well as to study changes in molecular structure or the formation of new chemical bonds. The spectrum of neat RAX (Figure 6) shows a 


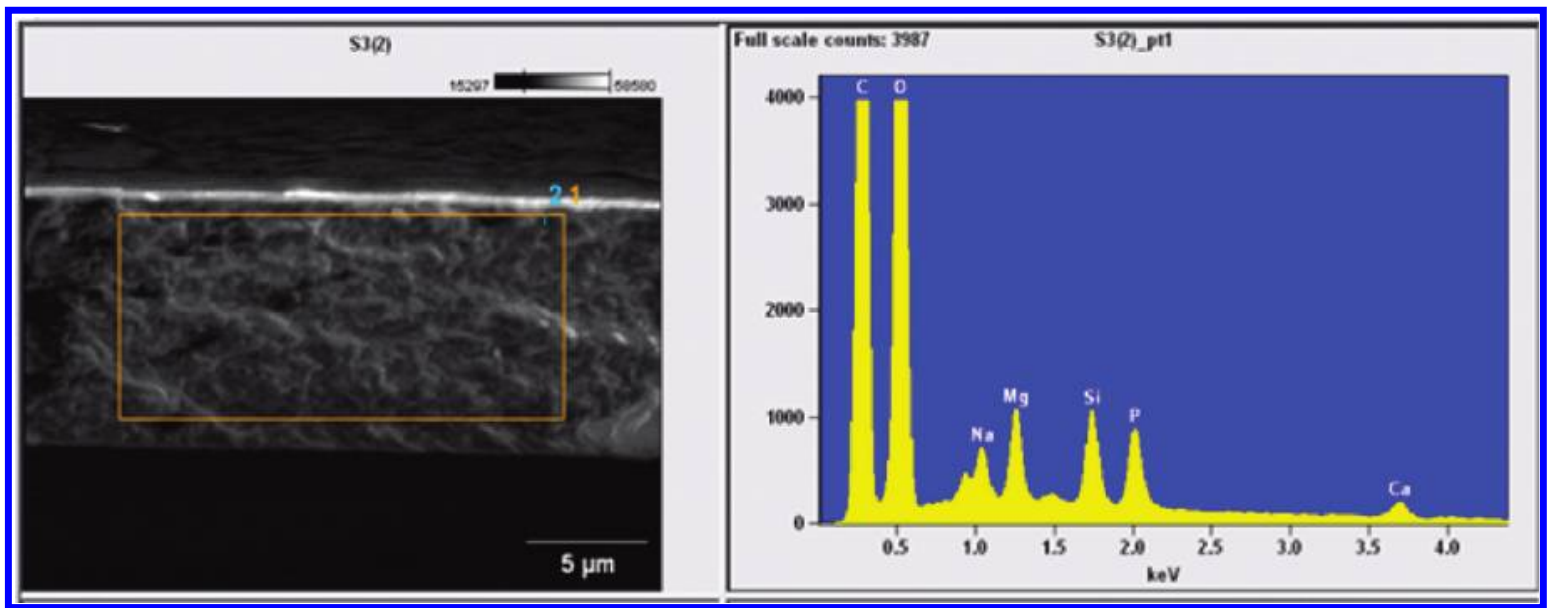

Figure 5. Low-magnification SEM image and corresponding EDX spectrum for the cross-section of a 95:5 rye arabinoxylan (RAX)-sepiolite composite film.

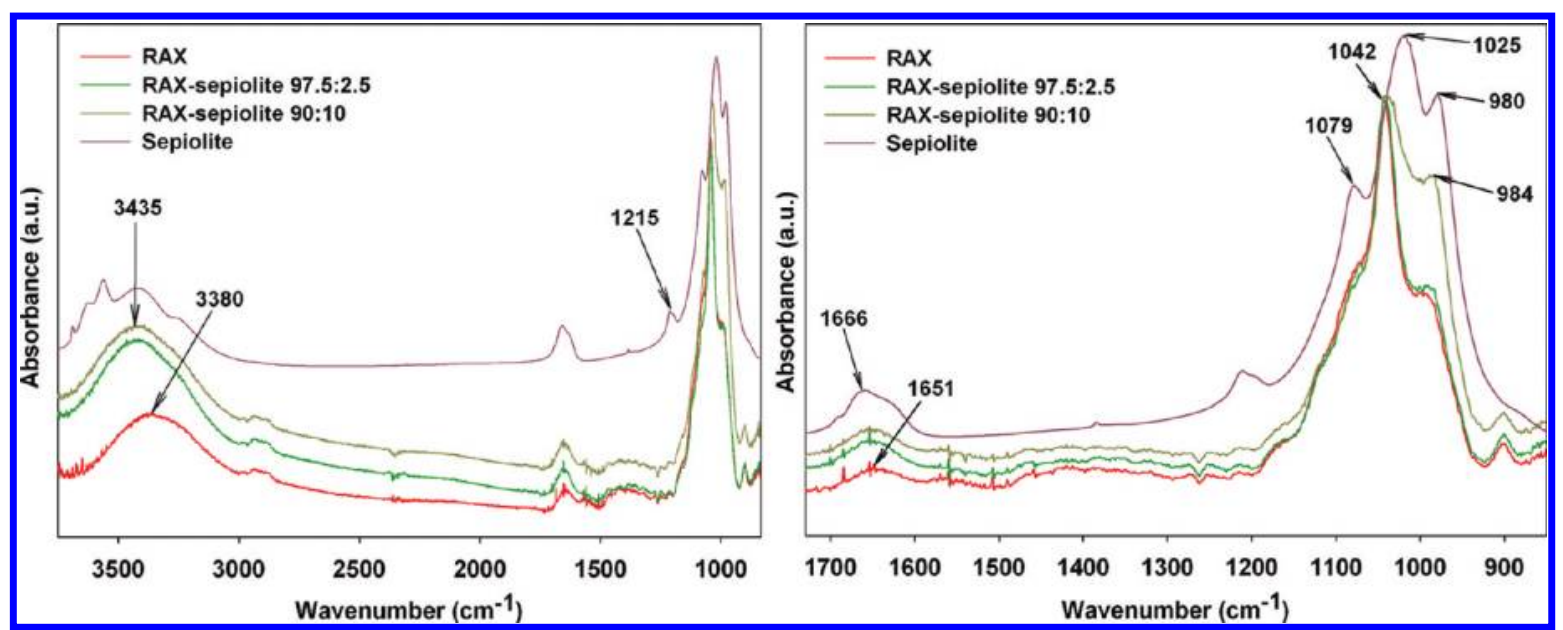

Figure 6. FT-IR spectra of sepiolite, neat rye arabinoxylan (RAX), and composites of RAX-sepiolite.

strong absorption band at $1042 \mathrm{~cm}^{-1}$, which is due to $\mathrm{C}-\mathrm{OH}$ bending. ${ }^{35,36}$ A weak absorption band at $900 \mathrm{~cm}^{-1}$ is characteristic of $\beta$ - $(1 \rightarrow 4)$ glycosidic linkages between the xylose units in the RAX structure. A low intensity amide I absorption band appears at approximately $1651 \mathrm{~cm}^{-1}$, which is consistent with a low level of protein contamination. ${ }^{37}$ The absence of an absorption band at $1517 \mathrm{~cm}^{-1}$ indicates that very little, if any, ferulic acid is present.

The FT-IR spectrum of sepiolite (Figure 6) shows peaks in the $3400-3650 \mathrm{~cm}^{-1}$ region attributed to $\mathrm{OH}$ stretching vibrations of zeolitic and $\mathrm{Mg}$-coordinated water molecules occurring inside the tunnels and bound to the magnesium ions in the mineral structure. Bending vibrations of the zeolitic or channel water molecules contributed to a signal at $1666 \mathrm{~cm}^{-1}$. Peaks associated with $\mathrm{Si}-\mathrm{O}$ bonds in the tetrahedral sheets were seen between 1300 and $800 \mathrm{~cm}^{-1}$. Si-O-Si bonds contributed to bands at 1215 and $1079 \mathrm{~cm}^{-1}$ and in-plane Si-O-Si vibrations were observed at $\sim 1025$ and $980 \mathrm{~cm}^{-1}$. 16,38

The spectra of RAX-sepiolite films show some differences when compared with the spectra of the pure components. The shoulder in the spectrum of RAX at $995 \mathrm{~cm}^{-1}$ grew with sepiolite addition and a peak appeared at $984 \mathrm{~cm}^{-1}$ in the spectrum of the RAX-sepiolite 90:10 film, which can be associated with the higher clay content of this film. A slight increase in the intensity of the peak at $1666 \mathrm{~cm}^{-1}$ was also noticed; however, there is overlap here with the RAX amide I band, which hinders interpretation. A peak appearing at 3380 $\mathrm{cm}^{-1}$ in the spectrum of the RAX film shifted toward higher wavenumbers with addition of sepiolite, as was observed for example at $3435 \mathrm{~cm}^{-1}$ in the spectrum of the RAX-sepiolite 90:10 film. This shift of the $\mathrm{OH}$ stretching band is likely indicative of hydrogen-bonding interactions between RAX and sepiolite.

X-ray Diffraction. Arabinoxylans with a high degree of substitution (Ara/Xyl ratio of 0.5 or greater) are amorphous and show no distinct peaks in the X-ray diffraction pattern. Decreasing the arabinose substitution (Ara/Xyl ratios between 0.37 and 0.2 ) on the xylan main chain can lead to increasing crystallinity, showing distinct crystalline peaks between 4.9 and $3.3 \AA^{3,39}$ It is believed that the unsubstituted regions of the chains crystallize while the more highly substituted regions of the xylan chains remain amorphous. The arabinoxylan (RAX) applied in this study was highly substituted (reported Ara/Xyl ratio of 0.64 ) and therefore the presence of a crystalline structure in the polymer was neither expected nor found. The neat RAX film exhibited a broad peak with a maximum at $4.5 \AA$ (Figure 7A).

The characteristic (110) diffraction of sepiolite dominates the pattern of the pure sepiolite sample (Figure 7E), and in addition, an unidentified impurity can be detected with a $d$ - 


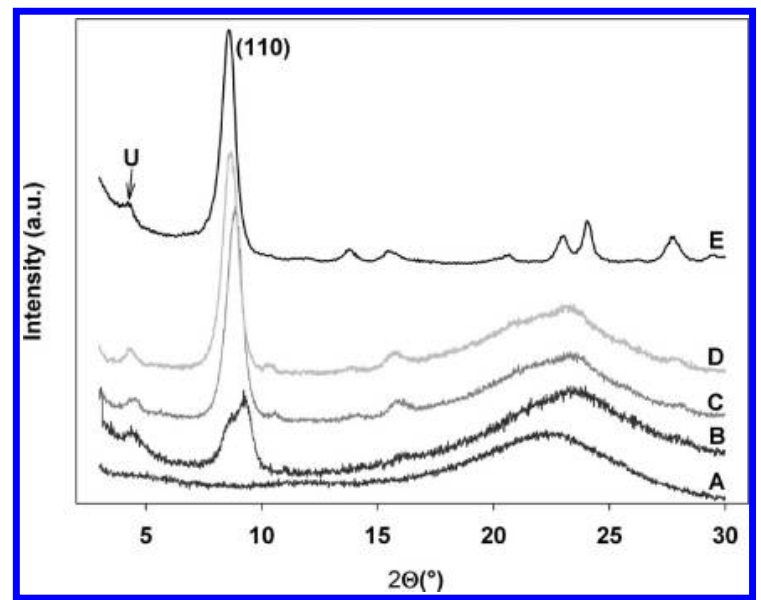

Figure 7. X-ray diffraction patterns of (A) neat rye arabinoxylan (RAX), (E) sepiolite and composite films of RAX-sepiolite, RAXsepiolite (B) 97.5:2.5, (C) 95:5, and (D) 90:10. (110) indicates the position of the characteristic peak from sepiolite and $U$ an unidentified mineral in the sepiolite sample.

spacing of $22.5 \AA$. A minor but distinct shift of the (110) diffraction can be observed in the composite films. This shift is caused by the off-set of the effective diffraction plane between the films and the shift scales with the effective density of the films. The maximum of the broad peak in the XRD pattern of the films is also shifted slightly toward higher angles (Figures 7A-D). This may signify a change in the polymer, but it is also influenced by overlapping with the minor diffraction peaks of the sepiolite.

TGA Analysis. The thermal properties of neat RAX and RAX-sepiolite films were studied using TGA under nitrogen atmosphere. Panels A and B in Figure 8 show the typical TGA

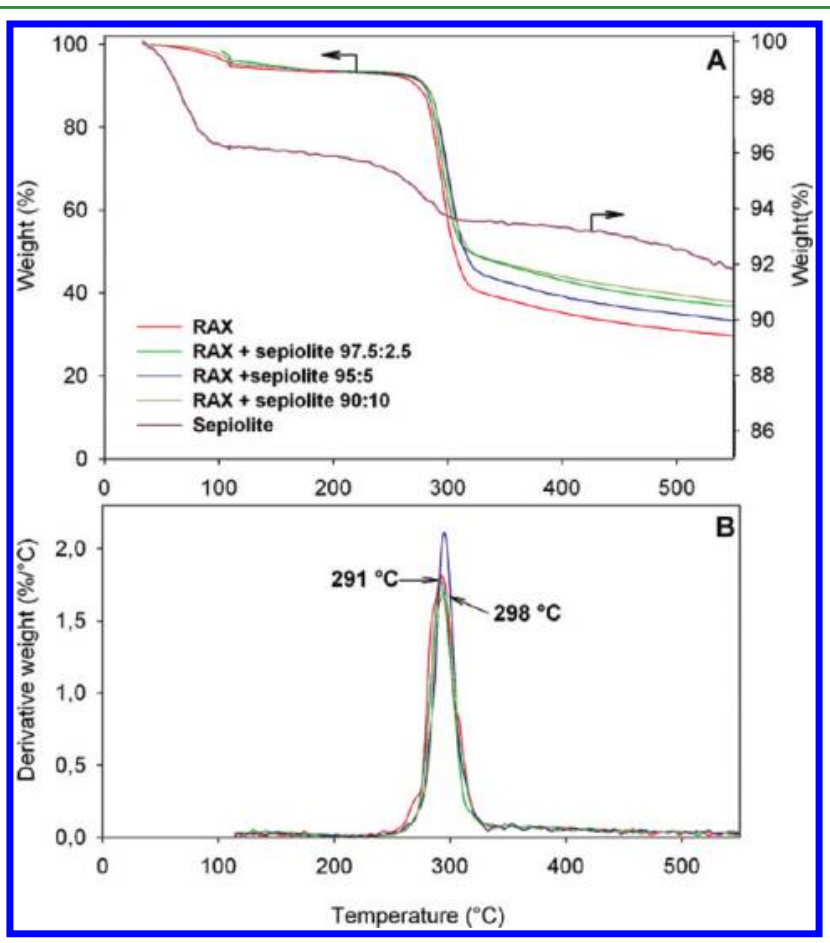

Figure 8. (A) TGA and (B) DTGA results for sepiolite, arabinoxylan (RAX), sepiolite, and composites of RAX and sepiolite in the temperature ranges $36-550^{\circ} \mathrm{C}$ and $110-550{ }^{\circ} \mathrm{C}$, respectively. and DTGA curves for RAX, RAX-sepiolite films and sepiolite powder. Sepiolite showed a weight loss of $11.1 \%$ in the temperature range $36-900{ }^{\circ} \mathrm{C}$ (the temperature range of $36-$ $550{ }^{\circ} \mathrm{C}$ is shown in Figure 8). Sepiolite loses zeolitic and structural water when it is heated and this is followed by loss of octahedrally coordinated hydroxyl groups (internal $\mathrm{Mg}-\mathrm{OH}$ ) in a four-step process with eventual collapse of the crystal structure. ${ }^{20,38}$ Kuang et al. ${ }^{20}$ found that maxima for the rate of weight loss occurred at $60{ }^{\circ} \mathrm{C}, 260{ }^{\circ} \mathrm{C}, 510{ }^{\circ} \mathrm{C}$ and $800-830^{\circ} \mathrm{C}$ and, except for the last two, these changes are shown in Figure $8 \mathrm{~A}$, representing the loss of zeolitic water, structural water in two stages, and $\mathrm{Mg}-\mathrm{OH}$ dehydroxylation, respectively. In Figure 8A, initial weight losses of approximately 5\% are attributable to the release of water. As shown, the arabinoxylan in the RAX and composite film samples started to decompose at $\sim 260{ }^{\circ} \mathrm{C}$. Slight differences in maximum weight loss temperatures $\left(T_{\max }\right)$ were observed in the DTGA. For example, RAX showed a $T_{\max }$ at $291{ }^{\circ} \mathrm{C}$, whereas $T_{\max }$ for the composite films containing $2.5,5$, and $10 \mathrm{wt} \%$ sepiolite were found at 295, 297 , and $298{ }^{\circ} \mathrm{C}$, respectively. A shift in $T_{\max }$ is commonly observed during thermal analysis of clay-biopolymer films. In one case, a similar temperature increase was found for starchsepiolite composites in which the $T_{\max }$ temperature increased 3 ${ }^{\circ} \mathrm{C}$ at 3 wt $\%$ sepiolite addition and $8{ }^{\circ} \mathrm{C}$ at $6 \mathrm{wt} \%$ sepiolite addition. ${ }^{12}$ Addition of layered nanoclays, such as MMT, has also been shown to increase degradation temperatures and in these cases the clay is thought to form an inorganic network, which can act as a gas transport barrier, thereby hindering the diffusion of pyrolysis gases. ${ }^{40}$ As a case in point, Ünlü et al. ${ }^{14}$ cast xylan films from corn cob with MMT addition and studied the thermal behavior of such films. A $T_{\max }$ of $284{ }^{\circ} \mathrm{C}$ was found for neat xylan but this increased to $303{ }^{\circ} \mathrm{C}$ with an addition of 2 $\mathrm{g} / \mathrm{mL} \mathrm{MMT}$ to $7.8 \times 10^{-5} \mathrm{~g} / \mathrm{ml}$ xylan. It seems reasonable to assume that the fibrous sepiolite would not so easily form a tortuous path to hinder the path of pyrolysis gases and, as a result, the increases in $T_{\max }$ are less significant (Figure $8 \mathrm{~B}$ ).

Tensile Testing. The effect of sepiolite addition on RAX film mechanical properties was examined by tensile testing. The efficiency of plasticization using $\mathrm{mPEG}$ addition was also studied. Neat arabinoxylan films without plasticizer addition showed a tensile strength (stress at break) of $42.5 \mathrm{MPa}$, which is similar to, but slightly lower than, values reported previously for this material. For example, Höije et al. ${ }^{35}$ and Stevanic et al. ${ }^{30}$ measured tensile strengths of 52.4 and $58 \mathrm{MPa}$ respectively for rye arabinoxylan at the same $\mathrm{RH}$, but at a slightly higher temperature in the work of Stevanic et al. Addition of sepiolite resulted in a very significant increase in film strength and stiffness (Table 1). As an example, addition of $2.5 \mathrm{wt} \%$ sepiolite to RAX gave an increase in Young's modulus from 2.3 to $3.9 \mathrm{GPa}$ and an increase in tensile strength from 42.5 to 73.6 $\mathrm{MPa}$. Further addition of sepiolite showed only a minor additional increase in the Young's modulus values. In the case of the tensile strength, although there was no significant difference between the mean values determined for films with 2.5 or $10 \mathrm{wt} \%$ sepiolite, there was a significantly lower mean value recorded for films with $5 \mathrm{wt} \%$ sepiolite. This particular finding is contrary to expectation and a detailed explanation must await further research. In general, it may be said that the nonplasticized films containing sepiolite had tensile strength values in the order of $70 \mathrm{MPa}$. No statistically significant differences were detectable in the strain at break values of the neat RAX and RAX-sepiolite composites without plasticizer addition. 
Table 1. Young's Modulus, Strain at Break, and Tensile Strength of Rye Arabinoxylan (RAX) and RAX-Sepiolite Composite Films ${ }^{a}$

\begin{tabular}{|c|c|c|c|}
\hline sample & $\begin{array}{l}\text { Young's } \\
\text { modulus } \\
(\mathrm{GPa})\end{array}$ & $\begin{array}{c}\text { strain at break } \\
(\%)\end{array}$ & $\begin{array}{l}\text { tensile strength } \\
\qquad(\mathrm{MPa})\end{array}$ \\
\hline RAX-sepiolite 90:10 & $4.3 \pm 0.1 \mathrm{~A}$ & $5.0 \pm 0.8 \mathrm{C}$ & $73.7 \pm 5.3 \mathrm{~A}$ \\
\hline RAX-sepiolite 95:5 & $4.2 \pm 0.2 \mathrm{~A}$ & $8.1 \pm 2.3 \mathrm{C}$ & $66.7 \pm 2.3 \mathrm{~B}$ \\
\hline RAX-sepiolite 97.5:2.5 & $3.9 \pm 0.3 \mathrm{~B}$ & $10.4 \pm 3.1 \mathrm{C}$ & $73.6 \pm 3.2 \mathrm{~A}$ \\
\hline RAX & $2.3 \pm 0.2 \mathrm{C}$ & $11.9 \pm 4.3 \mathrm{C}$ & $42.5 \pm 6.5 \mathrm{C}$ \\
\hline $\begin{array}{l}\text { RAX-sepiolite } 90: 10+ \\
\text { 30\% mPEG }\end{array}$ & $1.4 \pm 0.1 \mathrm{D}$ & $26.7 \pm 11 . \mathrm{B}$ & $24.9 \pm 5.1 \mathrm{~F}$ \\
\hline $\begin{array}{l}\text { RAX-sepiolite } 95: 5+ \\
\text { 30\% mPEG }\end{array}$ & $1.0 \pm 0.2 \mathrm{E}$ & $33.3 \pm 6.5 \mathrm{~B}$ & $26.6 \pm 2.3 \mathrm{EF}$ \\
\hline $\begin{array}{l}\text { RAX-sepiolite } 97.5: 2.5+ \\
\text { 30\% mPEG }\end{array}$ & $0.8 \pm 0.1 \mathrm{EF}$ & $44.4 \pm 7.8 \mathrm{~A}$ & $30.2 \pm 6.6 \mathrm{DE}$ \\
\hline $\mathrm{RAX}+30 \% \mathrm{mPEG}$ & $0.7 \pm 0.1 \mathrm{~F}$ & $42.0 \pm 9.7 \mathrm{~A}$ & $32.8 \pm 7.3 \mathrm{D}$ \\
\hline
\end{tabular}

${ }^{a} \mathrm{~A}, \mathrm{~B}, \mathrm{C}, \mathrm{D}, \mathrm{E}, \mathrm{F}$ : values with different superscript letters in the same column are statistically different (significance level of 0.05 ).

The addition of mPEG plasticizer had the expected effect of decreasing film stiffness and strength while increasing the elongation values. In the case of the RAX-sepiolite films with added mPEG, a slight increase in the Young's modulus and a decrease in the tensile strength values were observed with increasing sepiolite content. The strain at break showed values approximately four to five times higher than those of the nonplasticized films. A decrease in extensibility could be seen in films with 5 and $10 \mathrm{wt} \%$ sepiolite content and $30 \mathrm{wt} \% \mathrm{mPEG}$ relative to unfilled RAX or RAX films with $2.5 \mathrm{wt} \%$ sepiolite containing the same percentage of $\mathrm{mPEG}$.

The reinforcing effects of sepiolite addition have been investigated using other biopolymers such as chitosan and starch. Chivrac et al. ${ }^{12}$ incorporated 3 and 6 wt \% organomodified sepiolite into plasticized starch and found that the Young's modulus increased by up to a factor of 2.5 relative to unfilled wheat starch. As reported, a slight decrease was found in the strain at break values with sepiolite addition and with similar clay loading as applied in our study. Similar behavior when comparing layered silicates with sepiolite was observed in gelatin films. ${ }^{17}$ A reinforcing effect comparable to that reported here was observed and assigned to the presence of numerous silanol groups on the surface of the sepiolite fibers strongly interacting with the carbohydrate matrix. Darder et al., ${ }^{16}$ in their study on chitosan as the matrix, showed that sepiolite addition doubled the Young's modulus; however, this finding was obtained in the case of films containing very high sepiolite loadings. Such high sepiolite loadings (3-91 g of chitosan per $100 \mathrm{~g}$ of sepiolite) resulted in highly fragile films, hence strain at break was not measured and tensile strength values were not reported. With the addition of high sepiolite loadings, clay aggregation was observed in the cast films through the use of low-temperature SEM. Soler added MMT clay to arabinoxylan from barley husks and studied the reinforcing effects of MMT; however, significant effects in terms of tensile strength and Young's modulus were not seen. ${ }^{41}$ For example, the Young's modulus and tensile strength of arabinoxylan films were 1.3 $\mathrm{GPa}$ and $30.8 \mathrm{MPa}$, respectively, whereas the corresponding values for films reinforced with $11 \mathrm{wt} \% \mathrm{MMT}$ were $2.0 \mathrm{GPa}$ and $31.6 \mathrm{MPa}$.

Given the results presented here for the reinforcing effects of sepiolite fibers, it is interesting to make comparison with the effects introduced by other fibrous nanofillers. A significant increase in the tensile strength of hemicellulose films was previously seen when using cellulose nanofibers. Since the size of nanofibrillated cellulose is in a similar range to that of sepiolite fibers and both fillers have a high aspect ratio, similar behavior may be expected. Hemicellulose-cellulose nanocomposite mechanical properties are summarized in Table 2.

Table 2. Mechanical Properties of Xylan-Cellulose Nanocomposite Films

$\begin{array}{lccccc}\text { sample }^{a} & \begin{array}{c}\text { filler loading } \\ (\text { wt \%) }\end{array} & \text { ref } & \begin{array}{c}\text { Young's } \\ \text { modulus } \\ (\mathrm{GPa})\end{array} & \begin{array}{c}\text { tensile } \\ \text { strain at } \\ \text { break (\%) }\end{array} & \begin{array}{c}\text { strength } \\ (\mathrm{MPa})\end{array} \\ \mathrm{RAX} & 0 & 34 & 2.5 \pm 0.4 & 8.1 \pm 3.3 & 58 \pm 11 \\ \mathrm{RAX}+ & 15 & & 3.2 \pm 0.5 & 3.3 \pm 0.6 & 53 \pm 7 \\ \quad \mathrm{BC} & & & & & \\ \mathrm{AX}^{b} & 0 & 42 & 0.7 \pm 0.1 & 3.4 \pm 0.2 & 11.9 \pm 0.9 \\ \mathrm{AX}^{+} & 20 & & 3.4 \pm 0.1 & 1.4 \pm 0.1 & 39.5 \pm 2.2 \\ \quad \mathrm{NFC}^{b} & & & & & \\ \mathrm{X}^{c} & 0 & 43 & & \sim 22 & \sim 2.2 \\ \mathrm{X}+\mathrm{SW}^{c} & 10 & & & \sim 23 & \sim 5.9\end{array}$

${ }^{a} \mathrm{RAX}=$ rye arabinoxylan, $\mathrm{BC}=$ bacterial cellulose, $\mathrm{AX}=$ arabinoxylan, $\mathrm{NFC}=$ nanofibrillated cellulose, $\mathrm{X}=$ xylan from oat spelts, $\mathrm{SW}=$ sulfonated cellulose whisker. ${ }^{b}$ Added sorbitol plasticizer, $25 \%$ (percentage based on xylan content). ${ }^{c}$ Added sorbitol plasticizer, $50 \%$.

Peng et al. ${ }^{42}$ recently reported $\sim 300 \%$ increase in tensile strength and Young's modulus with 15 wt \% nanocellulose addition to bamboo arabinoxylan. In this case, nanocellulose was obtained by multihomogenization of bleached sisal pulp and had a reported aspect ratio of 50-100, based on a nanofibril diameter of $20 \pm 10 \mathrm{~nm}$ and length $>1000 \mathrm{~nm}$. Such significant increases in strength and stiffness were, however, not observed when rye arabinoxylan was reinforced using bacterial nanocellulose with similar dimensions as the sepiolite applied in this study. ${ }^{34}$ For example, the Young's modulus of arabinoxylan films showed $\sim 30 \%$ increase in the nanocomposite with $15 \%$ bacterial nanocellulose addition.

As concluded from the FT-IR results, interaction through hydrogen bonding between the sepiolite fibers and the RAX chains can be inferred and these interactions contribute to a great increase in the stiffness of the material. It is also apparent from the results that, above a clay content of $5 \mathrm{wt} \%$, fiber aggregation is more probable, which will contribute to the breakage of the films under tensile load and mean that further increases in tensile strength and Young's modulus are not likely to be detected. We may assume that the sepiolite fibers are themselves able to form a network, hence providing a reinforced composite material with superior mechanical properties compared to the neat RAX matrix. Considering the high aspect ratio of sepiolite fibers, a percolation threshold can be calculated. Since the dimensions of sepiolite fibers show a great variation in different reports, ${ }^{17,23,44}$ a range of calculated values can be obtained for the percolation threshold between $0.6 \%$ and $3.5 \%(\mathrm{v} / \mathrm{v})$ if a cylindrical sepiolite shape is assumed $\left(P_{c}=0.7 / r\right.$, where $P_{c}$ is the percolation threshold for cylindrical shaped particles and $r$ is the aspect ratio calculated from the ratio of length and diameter of sepiolite fibers). ${ }^{45}$ This calculation suggests that an added amount of sepiolite above the critical percolation threshold of approximately $2 \%(\mathrm{v} / \mathrm{v})$ would result in highly increased strength and stiffness in the materials. As supported by the tensile data presented here, films containing sepiolite at loadings much above the estimated $P_{c}$ do 
not show significant further increases in tensile strength and stiffness.

Barrier Properties. Water vapor barrier properties of cast RAX-sepiolite films were studied by measuring the water vapor permeability of the films using an ASTM method. The measured values were $2.6 \pm 0.3,2.5 \pm 0.0,3.3 \pm 0.4$, and 3.1 $\pm 0.3\left(\mathrm{~g} \mathrm{~mm} /\left(\mathrm{kPa} \mathrm{m}{ }^{2}\right.\right.$ day $\left.)\right)$ for the RAX, RAX + sepiolite 97.5:2.5, 95:5, and 90:10 films, respectively. These data show that sepiolite addition up to $10 \mathrm{wt} \%$ had no significant influence on water vapor permeability. Even though sepiolite might theoretically create a slightly longer and more difficult path for water molecules to diffuse through the films, sepiolite fibers are hydrophilic and embedded into a hydrophilic matrix with poor water vapor barrier properties. Hence, a positive effect in terms of reduced water vapor permeability is not seen. Further, the barrier effect commonly noted when plate-like clays are well dispersed in biopolymer films is not observed here, which is consistent with the different fibrous morphology of sepiolite and a lower probability that water vapor permeability will be reduced through a tortuous path effect. ${ }^{46}$ WVP values measured for the unfilled RAX reference film were lower or in the same range as values reported previously for nonplasticized arabinoxylan films extracted from corn hulls and bran. ${ }^{7,47}$

The effect of sepiolite addition on RAX film oxygen permeability was studied and the results are summarized in Table 3. RAX films showed low permeability values, between 0

Table 3. Oxygen Transmission Rate (OTR) and Oxygen Permeability (OP) of Neat Rye Arabinoxylan (RAX) and RAX-Sepiolite Composite Films at 50\% Relative Humidity and $23{ }^{\circ} \mathrm{C}^{a}$

\begin{tabular}{lcc}
\multicolumn{1}{c}{ type of film } & $\begin{array}{c}\text { OTR }\left(\mathrm{mL} /\left(\mathrm{m}^{2}\right.\right. \\
\text { day }))\end{array}$ & OP $\left(\mathrm{cm}^{3} \mu \mathrm{m} /\left(\mathrm{m}^{2}\right.\right.$ day $\left.\left.\mathrm{kPa}\right)\right)$ \\
RAX & $0.58-0.70$ & $0.15-0.22$ \\
RAX-sepiolite $97.5: 2.5$ & $0.80-1.41$ & $0.22-0.54$ \\
RAX-sepiolite $95: 5$ & $0.20-0.74$ & $0.10-0.26$ \\
RAX-sepiolite $90: 10^{b}$ & 0.69 & 0.19
\end{tabular}

${ }^{a}$ Values obtained from two measurements. ${ }^{b}$ Only one successful measurement could be made from the samples, because of leaking as a result of defects on the film surface.

and $1 \mathrm{~cm}^{3} \mu \mathrm{m} /\left(\mathrm{m}^{2}\right.$ day $\left.\mathrm{kPa}\right)$. Low OP values were expected since hemicellulose films have proven to be excellent oxygen barriers, with values in the range of $0.16-3.2 \mathrm{~cm}^{3} \mu \mathrm{m} /\left(\mathrm{m}^{2}\right.$ day $\mathrm{kPa})$ reported for similar hemicellulose film types. ${ }^{1,2,39}$ In this case, as with water vapor, sepiolite addition had no significant effect on oxygen permeability and, as above, the lack of a tortuous path effect when using a fibrous clay as additive may provide an explanation for these findings.

\section{CONCLUSIONS}

Transparent or semitransparent rye arabinoxylan (RAX) films containing 2.5-10 wt \% sepiolite were cast from aqueous suspensions and characterized by various physical methods. FTIR spectroscopy provided some evidence for hydrogen bonding between sepiolite and the RAX matrix. Strong interfacial bonding between sepiolite and the RAX matrix was illustrated by scanning electron microscopy and the good distribution of the clay was also shown using EDX imaging. Mechanical testing revealed very significant increases in the Young's modulus and tensile strength as a result of sepiolite addition, which exceeded previously reported values for xylan/nanocellulose or xylan/ MMT films. However, unlike layered nanoclays, addition of sepiolite fibers did not reduce the water vapor or oxygen permeability of RAX films and therefore other steps would need to be introduced in order to obtain higher gas barrier properties for specific applications.

\section{AUTHOR INFORMATION}

\section{Corresponding Author}

*Corresponding author. E-mail: dapl@kt.dtu.dk. Tel.:+45 4525-6813.

\section{Notes}

The authors declare no competing financial interest.

\section{ACKNOWLEDGMENTS}

Financial support for the research on xylan-sepiolite films undertaken as part of Zsuzsa Sárossy's $\mathrm{PhD}$ thesis and provided by the Technical University of Denmark is gratefully acknowledged. We thank Lei Shang (Department of Chemical and Biochemical Engineering, Technical University of Denmark) for her help with TGA analyses.

\section{REFERENCES}

(1) Gröndahl, M.; Gatenholm, P. In Materials, Chemicals, and Energy from Forest Biomass; Argyropoulos, D. S., Ed.; ACS Symposium Series, OUP; American Chemical Society: Washington, D.C., 2007; Vol. 954, p 137.

(2) Mikkonen, K. S.; Heikkinen, S.; Soovre, A.; Peura, M.; Serimaa, R.; Talja, R. A.; Helén, H.; Hyvönen, L.; Tenkanen, M. J. Appl. Polym. Sci. 2009, 114, 457-466.

(3) Zhang, Y.; Pitkänen, L.; Douglade, J.; Tenkanen, M.; Remond, C.; Joly, C. Carbohydr. Polym. 2011, 86, 852-859.

(4) Hansen, N. M. L.; Plackett, D. Biomacromolecules 2008, 9, 14931505.

(5) Ebringerová, A.; Heinze, T. Macromol. Rapid Commun. 2000, 21, $542-556$.

(6) Sternemalm, E.; Höije, A.; Gatenholm, P. Carbohydr. Res. 2008, 343, 753-757.

(7) Zhang, P.; Whistler, R. L. J. Appl. Polym. Sci. 2004, 93, 28962902.

(8) Ibn Yaich, A.; Edlund, U.; Albertsson, A. Biomacromolecules 2012, 13, 466-473.

(9) Mikkonen, K. S.; Heikkilä, M. I.; Willför, S. M.; Tenkanen, M. Int. J. Polym. Sci. 2012, 2012, 1-8.

(10) Saxena, A.; Elder, T. J.; Ragauskas, A. J. Carbohydr. Polym. 2011, 84, 1371-1377.

(11) Tartaglione, G.; Tabuani, D.; Camino, G.; Moisio, M. Compos. Sci. Technol. 2008, 68, 451-460.

(12) Chivrac, F.; Pollet, E.; Schmutz, M.; Avérous, L. Carbohydr. Polym. 2010, 80, 145-153.

(13) Viota, J. L.; Lopez-Viota, M.; Saake, B.; Stana-Kleinschek, K.; Delgado, A. V. J. Colloid Interface Sci. 2010, 347, 74-78.

(14) Ünlü, C. H.; Günister, E.; Atici, O. Carbohydr. Polym. 2009, 6, 585-592.

(15) Galan, E. Clay Miner. 1996, 31, 443-453.

(16) Darder, M.; López-Blanco, M.; Aranda, P.; Ruiz-Hitzky, E.; Aznar, A. J.; Bravo, J. Chem. Mater. 2006, 18, 1602-1610.

(17) Fernandes, F. M.; Manjubala, I.; Ruiz-Hitzky, E. Phys. Chem. Chem. Phys. 2011, 13, 4901-4910.

(18) Fukushima, K.; Tabuani, D.; Camino, G. Mater. Sci. Eng., C 2009, 29, 1433-1441.

(19) Olmo, N.; Lizarbe, M. A.; Gavilanes, J. G. Biomaterials 1987, 8, 67-69.

(20) Kuang, W.; Facey, G. A.; Detellier, C.; Casal, B.; Serratosa, J. M.; Ruiz-Hitzky, E. Chem. Mater. 2003, 15, 4956-4967. 
(21) Sakizci, M.; Erdogan Alver, B.; Yörükogullari, E. J. Therm. Anal. Calorim. 2011, 103, 435-441.

(22) Esteban-Cubillo, A.; Pina-Zapardiel, R.; Moya, J. S.; Barba, M.

F.; Pecharromán, C. J. Eur. Ceram. Soc. 2008, 28, 1763-1768.

(23) Bilotti, E.; Fischer, H. R.; Peijs, T. J. Appl. Polym. Sci. 2008, 107, $1116-1123$.

(24) Karakashev, S. I.; Ozdemir, O.; Hampton, M. A.; Nguyen, A. V. Colloids Surf., A 2011, 382, 132-138.

(25) Harris, J. M.; Chess, R. B. Nat. Rev. Drug Discov. 2003, 2, 214221.

(26) Siró, I.; Plackett, D.; Hedenqvist, M.; Ankerfors, M.; Lindström, T. J. Appl. Polym. Sci. 2011, 119, 2652-2660.

(27) ASTM D882-09 Standard Test Method for Tensile Properties of Thin Plastic Sheeting; ASTM International: West Conshohocken, PA, 2009.

(28) ASTM E96/E96M-05 Standard Test Methods for Water Vapor Transmittance of Materials; ASTM International: West Conshohocken, PA, 2005.

(29) Mikkonen, K. S.; Heikkilä, M. I.; Helén, H.; Hyvönen, L.; Tenkanen, M. Carbohydr. Polym. 2010, 79, 1107-1112.

(30) Gennadios, A.; Weller, C. L.; Gooding, C. H. J. Food Eng. 1994, 21, 395-409.

(31) Robertson, J. A.; Faulds, C. B.; Smith, A. C.; Waldron, K. W. J. Agric. Food Chem. 2008, 56, 1720-1726.

(32) Li, Y.; Jiang, Y.; Liu, F.; Ren, F.; Zhao, G.; Leng, X. Food Hydrocolloids 2011, 25, 1098-1104.

(33) Rhim, J. Carbohydr. Polym. 2011, 86, 691-699.

(34) Stevanic, J. S.; Joly, C.; Mikkonen, K. S.; Pirkkalainen, K.; Serimaa, R.; Rémond, C.; Toriz, G.; Gatenholm, P.; Tenkanen, M.; Salmén, L. J. Appl. Polym. Sci. 2011, 122, 1030-1039.

(35) Buslov, D. K.; Kaputski, F. N.; Sushko, N. I.; Torgashev, V. I.; Solov'eva, L. V.; Tsarenkov, V. M.; Zubets, O. V.; Larchenko, L. V. J. Appl. Spectrosc. 2009, 76, 801-805.

(36) Robert, P.; Marquis, M.; Barron, C.; Guillon, F.; Saulnier, L. J. Agric. Food Chem. 2005, 53, 7014-7018.

(37) Kacuráková, M.; Wellner, N.; Ebringerová, A.; Hromádková, Z.; Wilson, R. H.; Belton, P. S. Food Hydrocolloids 1999, 13, 35-41.

(38) Perraki, T.; Orfanoudaki, A. J. Therm. Anal. Calorim. 2008, 91, 589-593.

(39) Höije, A.; Sternemalm, E.; Heikkinen, S.; Tenkanen, M.; Gatenholm, P. Biomacromolecules 2008, 9, 2042-2047.

(40) Sinha Ray, S.; Okamoto, M. Prog. Polym. Sci. 2003, 28, 15391641.

(41) Soler, C. A. B. Preparation and Characterization of ArabinoxylanMontmorillonite Nanocomposites; Chalmers Univeristy of Technology: Göteborg, Sweden, 2008.

(42) Peng, X.; Ren, J.; Zhong, L.; Sun, R. Biomacromolecules 2011, 12, 3321-3329.

(43) Saxena, A.; Elder, T. J.; Pan, S.; Ragauskas, A. J. Composites, Part B 2009, 40, 727-730.

(44) Tunc, S.; Duman, O.; Cetinkaya, A. Colloids Surf., A 2011, 377, $123-129$.

(45) Yudin, V. E.; Otaigbe, J. U.; Svetlichnyi, V. M.; Korytkova, E. N.; Almjasheva, O. V.; Gusarov, V. V. eXPRESS Polym. Lett. 2008, 2, 485493.

(46) Grunlan, J. C.; Grigorian, A.; Hamilton, C. B.; Mehrabi, A. R. J. Appl. Polym. Sci. 2004, 93, 1102-1109.

(47) Peroval, C.; Debeaufort, F.; Despre, D.; Voilley, A. J. Agric. Food Chem. 2002, 50, 3977-3983. 